The documentation of euxinic and low sulphate conditions in mid-Proterozoic marine basins paves the way to an improved understanding of early life and environments. In such oceans, methanogenic archaeans could have played an enhanced role in the carbon cycle, contributing to long-lived greenhouse conditions ${ }^{27}$. Low sulphate may also help to explain the prominence of penecontemporaneous dolomite in mid-Proterozoic and older carbonate platform $\mathrm{s}^{28}$. Through its effects on biologically important trace elements, seawater chemistry may help to explain the ecological and evolutionary distributions of early eukaryotic photoautotrophs ${ }^{8}$. And, if sulphate levels remained low until the latest Proterozoic, oxygen probably also remained well below present levels, influencing the early diversification of animals ${ }^{29}$. Further biogeochemical research carried out in the framework of sequence stratigraphy ${ }^{30}$ should clarify the relationships between seawater chemistry and changes in the Proterozoic biosphere.

Received 14 November 2002; accepted 10 April 2003; doi:10.1038/nature01651.

1. Holland, H. D. in Early Life on Earth (ed. Bengtson, S.) 237-244 (Columbia Univ. Press, New York, 1994).

2. Farquhar, J., Bao, H. \& Thiemans, M. H. Atmospheric influence of the Earth's earliest sulphur cycle Science 289, 756-758 (2000).

3. Canfield, D. E., Habicht, K. S. \& Thamdrup, B. The Archean sulfur cycle and the early history of atmospheric oxygen. Science 288, 658-661 (2000).

4. Des Marais, D. J., Strauss, H., Summons, R. E. \& Hayes, J. M. Carbon isotopic evidence for the stepwise oxidation of the Precambrian environment. Nature 359, 605-609 (1992).

5. Derry, L. A., Kaufman, A. J. \& Jacobsen, S. B. Sedimentary cycling and environmental change in the late Proterozoic: evidence from stable and radiogenic isotopes. Geochim. Cosmochim. Acta 56, 1317-1329 (1992).

6. Canfield, D. E. \& Teske, A. Late Proterozoic rise in atmospheric oxygen concentrations inferred from phylogenetic and stable-isotope studies. Nature 382, 127-132 (1996)

Canfield, D. E. A new model for Proterozoic ocean chemistry. Nature 396, 450-453 (1998).

8. Anbar, A. D. \& Knoll, A. H. Proterozoic ocean chemistry and evolution: A bioinorganic bridge? Science 297, 1137-1142 (2002).

9. Abbott, S. T. \& Sweet, I. P. Tectonic control on third-order sequences in a siliciclastic ramp-style basin an example from the Roper Superbasin (Mesoproterozoic), northern Australia. Aust. J. Earth Sci. 47, 637-657 (2000).

10. Raiswell, R. \& Canfield, D. E. Sources of iron for pyrite formation in marine sediments. Am. J. Sci. 298, 219-245 (1998)

11. Raiswell, R., Newton, R. \& Wignall, P. B. An indicator of water-column anoxia: resolution of biofacies variations in the Kimmeridge clay (upper Jurassic, U.K.). J. Sedim. Res. 71, 286-294 (2001).

12. Shen, Y., Canfield, D. E. \& Knoll, A. H. Middle Proterozoic ocean chemistry: Evidence from the McArthur Basin, northern Australia. Am. J. Sci. 302, 81-109 (2002).

13. Wijsman, J. W. M., Middelburg, J. J., Herman, P. M. J., Böttcher, M. E. \& Heip, C. H. R. Sulfur and iron speciation in surface sediments along the northwestern margin of the Black Sea. Mar. Chem. 74, 261-278 (2001).

14. Jackson, M. J. \& Raiswell, R. Sedimentology and carbon-sulphur geochemistry of the Velkerri Formation, a mid-Proterozoic potential oil source in northern Australia. Precambr. Res. 54, 81-108 (1991).

15. Hayes, J. M., Lambert, I. B. \& Strauss, H. in The Proterozoic Biosphere: A Multidisciplinary Study (eds Schopf, J. W. \& Klein, C.) 129-134 (Cambridge Univ. Press, Cambridge, 1992).

16. Canfield, D. E. \& Raiswell, R. The evolution of the sulfur cycle. Am. J. Sci. 299, 697-723 (1999).

17. Muir, M. D., Donnelly, T. H., Wilkins, R. W. T. \& Armstrong, K. J. Stable isotope, petrological, and fluid inclusion studies of minor mineral deposits from the McArthur Basin: implications for the genesis of some sediment-hosted base metal mineralization from the Northern Territory. Aust. J. Earth Sci. 32, 239-260 (1985)

18. Zaback, D. A., Pratt, L. M. \& Hayes, J. M. Transport and reduction of sulfate and immobilization of sulfide in marine black shales. Geology 21, 141-144 (1993).

19. Donnelly, T. H. \& Crick, I. H. Depositional environment of the middle Proterozoic Velkerri Formation in northern Australia: geochemical evidence. Precambr. Res. 42, 165-172 (1988).

20. Lyons, T. W. Sulfur isotopic trends and pathways of iron sulphide formation in upper Holocene sediments of the anoxic Black Sea. Geochim. Cosmochim. Acta 61, 3367-3382 (1997).

21. Gautier, D. Cretaceous shales from the western interior of North America: sulfur/carbon ratios and sulfur isotope composition. Geology 14, 225-228 (1986).

22. Logan, G. A., Hayes, J. M., Hieshima, G. B. \& Summons, R. E. Terminal Proterozoic reorganization of biogeochemical cycles. Nature 376, 53-56 (1995).

23. Lyons, T. W., Luepke, J. J., Schreiber, M. E. \& Zeig, G. A. Sulfur geochemical constraints on Mesoproterozoic restricted marine deposition: lower Belt Supergroup, northwestern United States. Geochim. Cosmochim. Acta 64, 427-437 (2000).

24. Strauss, H. \& Schieber, J. A sulfur isotope study of pyrite genesis: The Mid-Proterozoic Newland Formation, Belt Supergroup, Montana. Geochim Cosmochim Acta 54, 197-204 (1990).

25. Kah, L. C., Lyons, T. W. \& Chesley, J. T. Geochemistry of a 1.2 Ga carbonate-evaporite succession, northern Baffin and Bylot Islands: implications for Mesoproterozoic marine evolution. Precambr. Res. 111, 203-234 (2001).

26. Hurtgen, M. T., Arthur, M. A., Suits, N. S. \& Kaufman, A. J. The sulfur isotopic composition of Neoproterozoic seawater sulfate: implications for a snowball Earth? Earth Planet. Sci. Lett. 203, 413-429 (2002).

27. Pavlov, A. A., Hurtgen, M. T., Kasting, J. F. \& Arthur, M. A. Methane-rich Proterozoic atmosphere? Geology 31, 87-90 (2003).
28. Baker, P. A. \& Kastner, M. Constraints on the formation of sedimentary dolomite. Science 213, 214-216 (1981).

29. Knoll, A. H. \& Carroll, S. B. Early animal evolution: emerging views from comparative biology and geology. Science 284, 2129-2137 (1999).

30. Ross, G. M., Bloch, J. D. \& Krouse, H. R. Neoproterozoic strata of the southern Canadian Cordillera and the isotopic evolution of seawater sulfate. Precambr. Res. 73, 71-99 (1995).

Supplementary Information accompanies the paper on www.nature.com/nature.

Acknowledgements We thank A. Bauer and J. Brocks for help in sample collection, J. Fong and L. Liu for help with geochemical analysis, J. Payne for help with statistics, and D. Canfield, J. Hayes, M. Hurtgen, T. Lyons and G. Ross for comments and suggestions. This study was supported by an NRC Research Associateship (Y.S.), the NASA Exobiology programme, the Astrobiology Institute, Macquarie University, and the Australian Research Council.

Competing interests statement The authors declare that they have no competing financial interests.

Correspondence and requests for materials should be addressed to Y.S. (yshen@oeb.harvard.edu).

\section{Stability of forest biodiversity}

\section{James S. Clark \& Jason S. McLachlan}

Center on Global Change, Biology, and Nicholas School of the Environment, Duke University, Durham, North Carolina 27708, USA

Two hypotheses to explain potentially high forest biodiversity have different implications for the number and kinds of species that can coexist and the potential loss of biodiversity in the absence of speciation. The first hypothesis involves stabilizing mechanisms, which include tradeoffs between species in terms of their capacities to disperse to sites where competition is weak ${ }^{1-4}$, to exploit abundant resources effectively ${ }^{5,6}$ and to compete for scarce resources ${ }^{7}$. Stabilization results because competitors thrive at different times and places. An alternative, 'neutral model' suggests that stabilizing mechanisms may be superfluous. This explanation emphasizes 'equalizing' mechanisms', because competitive exclusion of similar species is slow. Lack of ecologically relevant differences means that abundances experience random 'neutral drift', with slow extinction ${ }^{9-11}$. The relative importance of these two mechanisms is unknown, because assumptions and predictions involve broad temporal and spatial scales. Here we demonstrate that predictions of neutral drift are testable using palaeodata. The results demonstrate strong stabilizing forces. By contrast with the neutral prediction of increasing variance among sites over time, we show that variances in post-Glacial tree abundances among sites stabilize rapidly, and abundances remain coherent over broad geographical scales.

It is difficult to test competing hypotheses for coexistence. In ecological models, stable coexistence typically requires tradeoffs. Communities may be 'packed', in the sense that only species with particular life history combinations can coexist ${ }^{3}$. The potential importance of stabilizing forces has led to searches for tradeoffs that partition advantages in space and time between different species $^{12}$. Although some types of tradeoffs are clear-cut, such as those characterizing early and late successional species ${ }^{13,14}$, the overall importance of tradeoffs is debatable ${ }^{10,12,15}$.

By contrast, if species differences are small, the inherent limits to diversity implied by specific types of competition may not apply. The neutral model does not refer to a strict random walk, because finite space limits the density of trees. Rather, ecological equivalence allows that abundances drift randomly. Speciation might balance losses, provided that new species are generated as rapidly as random extinction removes them. Although there are unique temporal patterns associated with processes such as random drift, for trees 
the dynamics are too slow to quantify adequately. Fossil pollen records represent time series of species abundance, but statistical tests for a random walk (see for example ref. 16) are not powerful. Thus, the case for lack of tradeoffs typically appeals to indirect evidence, such as the obvious similarities shared by many tree species $^{10}$, and spatial patterns or dominance-diversity curves ${ }^{11}$ that might be compatible with multiple mechanisms. Hubbell ${ }^{11}$ suggests that, even if wrong, difficult to test, or both, the hypothesis of random drift might serve as a useful 'null' model.

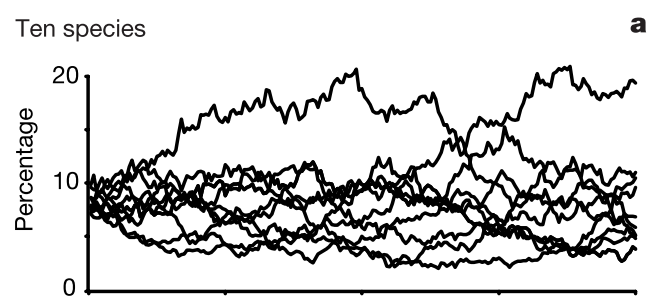

One species across eight sites b

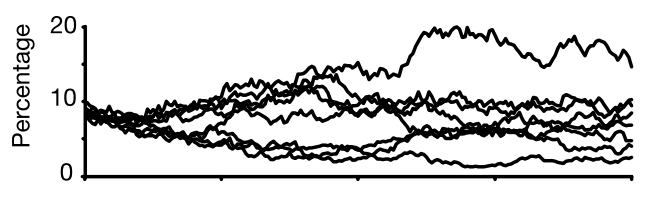

Variance across eight sites c

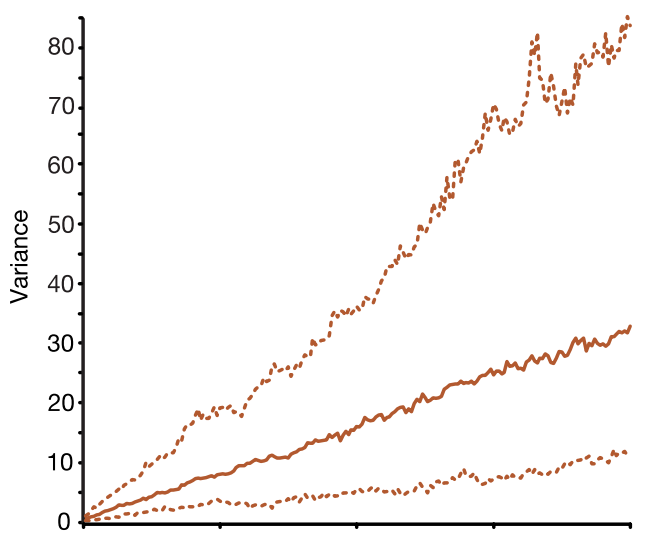

CV across eight sites d

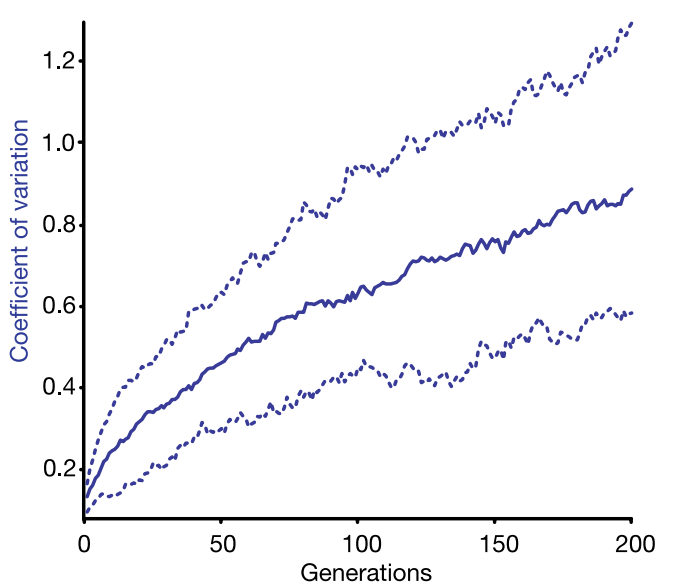

Figure 1 Simulations of neutral dynamics showing the divergence among sites. a, Lottery model, where ten species with identical parameters and responses to stochasticity compete for space. $\mathbf{b}$, Results for a single species shown for eight different sites. Abundances diverge with the random accumulation of changes at each site. c, Variance among sites increases over time owing to accumulation of the random changes in abundance shown in $\mathbf{b}$, as does (d) the coefficient of variation, CV. In $\mathbf{c}$ and $\mathbf{d}$, the middle line indicates the median, and the dashed lines bound $90 \%$ of simulated values.
Tests of neutral drift are available, provided that we exploit both temporal and spatial information from fossil pollen data, as opposed to trends in an individual series. If community dynamics are characterized by random drift, then variances among sites increase over time, with the accumulation of random changes in abundance. This is true even if the process is not strictly neutral (see Methods). For example, Fig. 1a illustrates a lottery process for species having identical parameters, where responses to stochasticity do not depend on species identity. To stress the fact that variance among sites increases rapidly over time, our simulation example assumes within-site variances that are substantially lower than we calculate from fossil data. Drift results in rapid accumulation of among-site variance (Fig. 1b, c), which is readily identifiable and would continue to increase until much of the diversity was lost through extinction. This trend is also predicted for the coefficient of variation (Fig. 1d), which, unlike the variance, does not increase simply because absolute abundance increases.

We analysed trends in variance among sites from a portion of eastern North America during the Holocene epoch. Fossil pollen that accumulates in lake sediments records changes in the relative abundances of species over geological timescales, but with temporal resolution that is compatible with tree generation times $(10$ to $\sim 100$ years). The fossil pollen record integrates abundances over scales of a 'stand' (small lakes) to a region (large lakes) ${ }^{17,18}$. Sites used here are distributed over more than $10^{4} \mathrm{~km}^{2}$, an area large enough that dynamics are mutually independent; rare, long-distance dispersal is not sufficient to synchronize dynamics between sites. Thus, it represents a useful scale for assessing the degree to which populations may engage in neutral dynamics (see Methods).

To test the hypothesis that abundances drift at random, we determined changes in means and variances for the past $10,000 \mathrm{yr}$ (as dated by ${ }^{14} \mathrm{C}$ ), a period of more than 200 tree generations, at eight sites. This interval spans a time of rapid climate change followed by modest climate changes typical of those prevailing in forests postulated to show neutral drift. The interval is not free of external influences. Indeed the rapid climate changes at the beginning of the Holocene and the large-scale changes in hemlock (Tsuga) abundance (probably caused by a natural enemy ${ }^{19}$ ) lend additional insight into the neutral hypothesis. Climate fluctuations contribute variance to populations. Failure to observe the rise in variance predicted by neutral dynamics would be especially strong evidence for stabilizing forces, which would have to overcome the tendency of climate variability, disturbance and the hemlock decline to increase variability. We used regression to assess trends in amongsite variance over time.

Our results are not consistent with neutral drift. Contrary to predictions (Fig. 1), following expansion in the early Holocene the relative abundances of all dominant pollen taxa reach relatively constant values, and variances and coefficients of variation among sites tend to stabilize or decline (Fig. 2). The expansion persists well into the Holocene at these mid-latitude sites and is characterized by increasing pollen percentages, attended by a rise in among-site variance. The initial increases in among-site variance result from increase in total abundance, not from drift, as is shown by coefficients of variation. The percentages for a given taxon subsequently tend to stabilize at each site. In contrast with neutral drift (Fig. 1c), none of the changes in variance are significant (Fig. 2). Only Betula and Quercus show evidence of increasing variance during the past few millennia. For both taxa, this trend follows declining variances of the mid-Holocene, and it results from increasing abundances and not from divergence among sites. Moreover, Acer, Fagus, Fraxinus and Ulmus all show declining variances among sites in the latter half of the Holocene.

Tsuga canadensis provides especially compelling evidence for stabilizing mechanisms, and in a different way. Following disturbance, stabilizing forces are expected to return populations to their former abundances. By contrast, the neutral model predicts that 
population densities should continue to drift at random, with no propensity to return to previous abundances. In all eight cases, the synchronous collapse of this population across eastern North America at $4750{ }^{14} \mathrm{C}$ yr BP (ref. 20) was followed by return to abundances close to those prevalent before its decline. The fact that this occurs across eastern North America provides strong evidence that stabilizing mechanisms maintain species abundances, and it is not consistent with neutral drift.

We selected a specific region for our analysis for purposes of demonstration, but the results can be generalized. Pollen data from temperate and boreal regions that have abundant pollen records share the characteristics of geographical coherence and continuity $^{21,22}$. We could not complete this analysis for tropical forests as lake sediments are not readily available. Nonetheless, relatively constant pollen abundances spanning much of the Holocene are typical of the Tropics ${ }^{23}$, consistent with our results and indicating that stabilizing mechanisms are not limited to temperate latitudes.

Our results provide strong evidence for stabilizing mechanisms. Populations did not achieve random densities following deglaciation at the end of the Pleistocene and neutrally drift thereafter. Rather, the strong geographical coherence in early Holocene pollen abundances and broad consistency in variances among sites point to stabilizing effects. Even the collapse of a dominant late-successional species, hemlock, saw recovery to relative abundances typical of pre-collapse populations.

Taken together, these aspects of the palaeo-record point to the
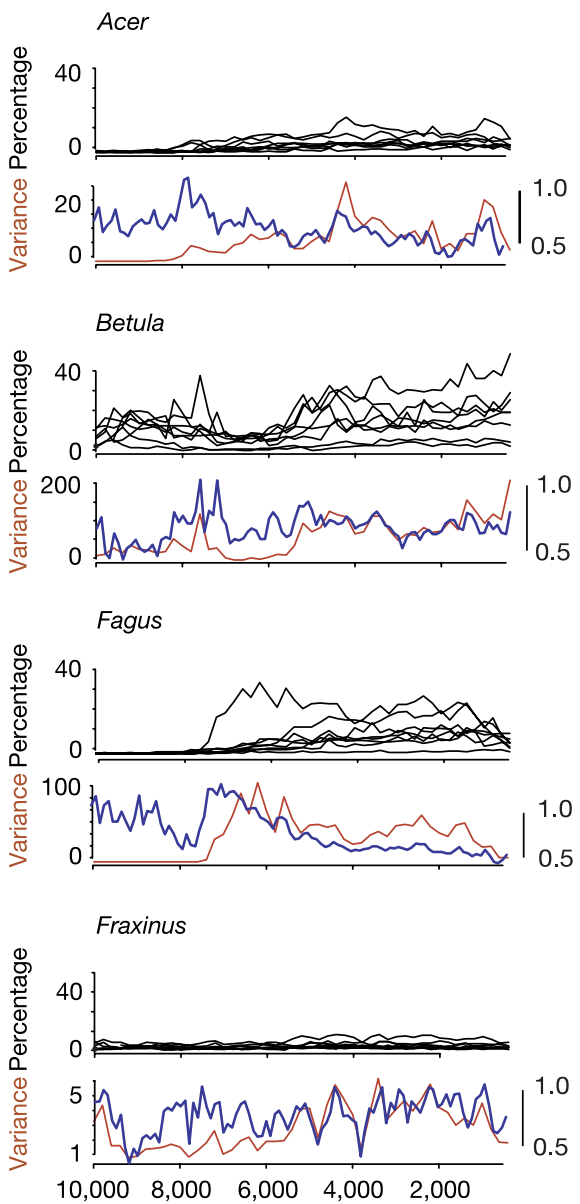

importance of stabilizing mechanisms that maintain tree populations within bounded densities which are geographically and temporally coherent. This evidence does not, in itself, demonstrate a role for tradeoffs in any specific sense. It does indicate the importance of stabilizing mechanisms that might derive from species differences, in terms of their capacities to colonize new sites, exploit abundant resources and tolerate competition ${ }^{3-8}$. Individual-level variability can result in large overlap among species, but the effect can be stabilizing ${ }^{12,15}$. Stochasticity associated with colonization, growth and survival can have a strong stabilizing influence that contrasts with the slow drift to extinction or dominance implied by neutral dynamics ${ }^{8,12,15}$. Our results do not imply that the equalizing mechanisms stressed in the neutral model are absent or inconsequential ${ }^{9-11}$, only that they must operate together with strong stabilizing forces.

A neutral interpretation of forest dynamics requires that continual (albeit potentially slow) extinction losses are offset by persistent speciation ${ }^{9,11}$. This implies that modern diversity levels owe much to continual emergence of new species. We did not test the neutral drift model using speciation and extinction data for two reasons. First, speciation and extinction rates are invoked to explain why diversity does not eventually collapse with neutral drift, but neutral drift can be tested on its own. Speciation and extinction can occur whether dynamics are controlled by stabilizing forces or by neutral drift. Second, the palaeo-record is inadequate for tests of speciation and extinction. Whereas patterns of extinction and

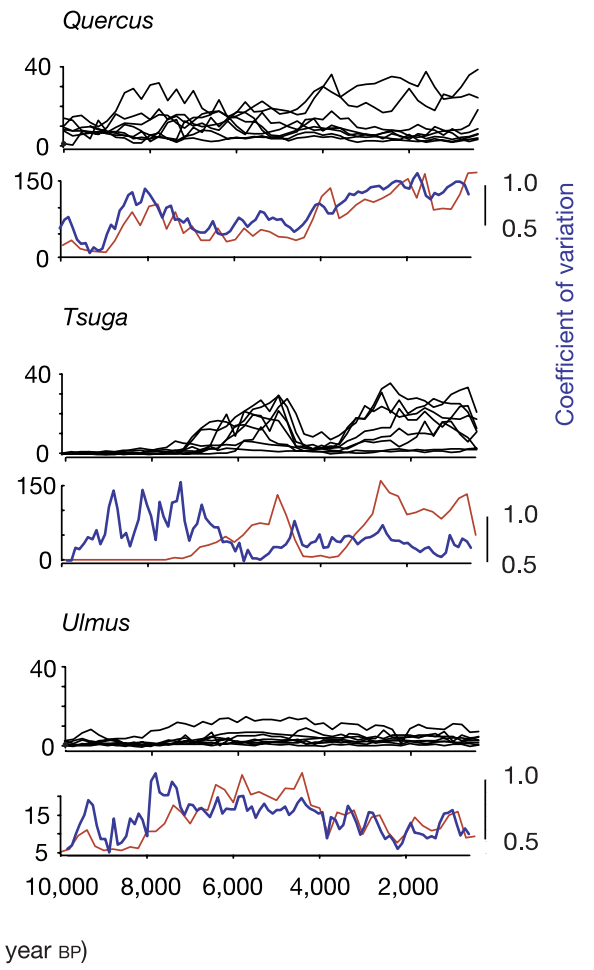

Figure 2 Fossil pollen data for seven dominant taxa from eight sites in Ontario. In contrast to 'neutral' changes in $\mathbf{a}$, abundances of all taxa at all sites tend to stabilize soon after expansion. Although the variances within each series are much larger than those used for

simulation, the variances (brown) and coefficients of variation (blue) among sites do not increase. 
speciation are poorly known and, by themselves, do not identify mechanisms, geographical patterns in variance are compelling. Our analysis demonstrates that drift is inconsistent with evidence that is readily available for the Holocene.

The strong evidence for stabilizing forces in the palaeo-record has implications different from those of neutral drift. If modern diversity levels have been maintained by stabilizing forces, rather than by incessant replenishment through speciation, then high contemporary extinction rates are likely to have more profound and enduring impacts on future biodiversity.

\section{Methods}

\section{Data}

Fossil pollen percentages were obtained from the North American Pollen Database (http://www.ngdc.noaa.gov/paleo/pollen.html). The eight sites come from southern Ontario, where there exists an unusually high density of small lakes (Table 1). These sites are small enough to emphasize local dynamics, they share regional climate and vegetation histories, and they are spaced broadly enough to allow comparisons among sites. To calculate variances among sites, we generated evenly spaced series at 200 -yr intervals by linear interpolation from 10,000 to $200{ }^{14} \mathrm{Cyr}$ в. Two of the lakes show evidence of pre-Columbian agriculture (Second and Tonawa Lakes), which could affect tree abundances, but omission of these sites did not change the results.

Pollen data are not the same as tree data, and the relationships between them influenced our modelling approach. Pollen abundances are sometimes fitted to models of population dynamics. Pollen accumulation rate is typically used with such applications, and it is compatible with models of population growth rate. Those models can be interpreted in terms of either population density or abundance. The lottery model is appropriate for assessment of neutral dynamics, and it assumes relative abundance. We therefore use pollen percentages, not pollen accumulation. Because different taxa produce different amounts of pollen, the relative abundance of pollen is not the same as the relative abundance of trees. Here again, a lottery model is appropriate, because the predicted trends in variance hold even for arbitrary weightings of species. The fact that some pollen taxa include more than one species does not affect the assessment of this mechanism. We could view pollen percentages as the sums of random variables, and the spatial variance among those sums would also increase with time. Declines in variance, coefficient of variation, or both for the monospecific taxa (Fagus, Tsuga) confirm that individual species also show strong evidence of stabilizing forces.

\section{Simulation model}

'Neutrality' can be viewed in several ways. Regardless of the specific model, we simply point out that abundances among sites tend to diverge over time. This is true whether the process is a simple random walk or there is some constraint on total density. A random walk on log density could be written as

$$
n_{i, j}(t+1)=n_{i, j}(t) e^{\varepsilon_{i, j}(t)}
$$

for density $n_{i, j}(t)$ of species $i$ at location $j$ at time $t$, and stochasticity might be represented as $\varepsilon_{i, j}(t) \sim N\left(0, \sigma^{2}\right)$, with variance $\sigma^{2}$. Variance among sites $j$ increases linearly with time. In this model, there are no bounds on total density. Density-dependent versions of this model $^{24}$ also show divergence across sites.

Some descriptions of 'neutrality' are better represented by a lottery model than by a random walk, because the space available is finite. To illustrate trends in abundance among sites $j$, consider a simple lottery

$$
n_{i, j}(t+1)=\left(1-\delta_{i}\right) n_{i}(t)+n_{i}(t) \sum_{k=1}^{m} \delta_{k} n_{k j}(t) \frac{\beta_{i}(t) n_{i j}(t)}{\sum_{k=1}^{m} \beta_{k}(t) n_{k j}(t)}
$$

with mortality rate $\delta_{i}$, and stochastic recruitment rate $\beta_{i}(t) \propto \operatorname{Pois}\left(b_{i}\right)$ The first term in equation (1) is survival. The second term is new recruitment, being the product of new sites opened by mortality and the fraction of those sites that are obtained by species $i$. Although the state variable $n(t)$ is continuous, our discrete recruitment allows random changes in population to have an effect at low density. Stable coexistence results, provided that species differ in how they respond to stochasticity, which, in this case, is associated with recruitment.

Neutrality implies not only that parameters are identical for all species

$$
\delta_{i} \equiv \delta \text { and } b_{i} \equiv b, i=1, \ldots, m
$$

\begin{tabular}{|c|c|c|c|c|}
\hline \multicolumn{5}{|c|}{ Table 1 Lakes and references for sites analysed in Fig. 2} \\
\hline Site & Latitude $\left({ }^{\circ} \mathrm{N}\right)$ & Longitude $\left({ }^{\circ} \mathrm{W}\right)$ & Elevation (m) & Reference \\
\hline Lac Bastien & 46.24 .00 & 78.55 .00 & 305 & 25 \\
\hline Decoy Lake & 43.14 .00 & 80.22 .00 & 260 & 26 \\
\hline Graham Lake & 45.11 .00 & 77.21 .00 & 381 & 27 \\
\hline Hams Lake & 43.14 .12 & 80.24 .48 & 301 & 25 \\
\hline High Lake & 44.31 .00 & 76.36 .00 & 192 & 27 \\
\hline Nutt Lake & 45.13 .00 & 79.27 .00 & 305 & 25 \\
\hline Second Lake & 44.51 .00 & 79.58 .48 & 196 & 28 \\
\hline Tonawa Lake & 44.51 .00 & 77.10 .30 & 274 & 29 \\
\hline
\end{tabular}

but also that they respond identically to stochasticity. We can remove distinctions among Ecology 53, 749-752 (1972).

2. Hastings, A. Disturbance, coexistence, history, and competition for space. Theor. Pop. Biol. 18, 363-373 (1980).

3. Tilman, D. Competition and biodiversity in spatially structured habitats. Ecology 75, 2-16 (1994).

4. Hixon, M. A., Pacala, S. W. \& Sandin, S. A. Population regulation: historical context and contemporary challenges of open vs. closed systems. Ecology 83, 1490-1508 (2002).

5. Pacala, S. W. \& Rees, M. Field experiments that test alternative hypotheses explaining successional diversity. Am. Nat. 152, 729-737 (1998).

6. Bolker, B. M. \& Pacala, S. W. Spatial moment equations for plant competition: understanding spatial strategies and the advantage of short dispersal. Am. Nat. 153, 575-602 (1999).

7. Tilman, D. Plant Strategies and the Dynamics and Structure of Plant Communities (Princeton Univ. Press, Princeton, New Jersey, 1998).

8. Chesson, P. Mechanisms of maintenance of species diversity. Annu. Rev. Ecol. Syst. 31, 343-366 (2000).

9. Hubbell, S. P. \& Foster, R. B. in Community Ecology (eds Diamond, J. \& Case, T. J.) 314-330 (Harper and Row, New York, New York, 1986).

10. Hubbell, S. P. et al. Light gap disturbances, recruitment limitation and tree diversity in a neotropical forest. Science 283, 554-557 (1999).

11. Hubbell, S. P. The Unified Neutral Theory of Biodiversity and Biogeography (Princeton Univ. Press, Princeton, New Jersey, 2001).

12. Clark, J. S., Dietze, M., Ibanez, I. \& Mohan, J. Coexistence: how to discriminate trophic tradeoffs from slow dynamics. Ecology (in the press).

13. Huston, M. \& Smith, T. Plant succession: life history and competition. Am. Nat. 130, 168-198 (1987),

14. Rees, M., Condit, R., Crawley, M., Pacala, S. \& Tilman, D. Long term studies of vegetation dynamics. Science 293, 650-655 (2001).

15. Clark, J. S., LaDeau, S. \& Ibanez, I. Fecundity of trees and the colonization-competition hypothesis Ecological Monog. (in the press).

16. Dickey, D. A. \& Fuller, W. A. Distribution of the estimators for autoregressive time series with a unit root. J. Am. Stat. Assoc. 74, 427-431 (1979).

17. Jacobson, G. L. \& Bradshaw, R. H. W. The selection sites for paleovetational studies. Quat. Res. 16, 80-96 (1981).

18. Prentice, I. C. Pollen representation, source area, and basin size: toward a unified theory of pollen analysis. Quat. Res. 23, 76-86 (1985).

19. Allison, T. D., Moeller, R. E. \& Davis, M. B. Pollen in laminated sediments provides evidence for a midHolocene forest pathogen outbreak. Ecology 67, 1101-1105 (1986).

20. Bennett, K. D. \& Fuller, J. L. Determining the age of the mid-Holocene Tsuga canadensis (hemlock) decline in eastern North America. Holocene 12, 421-429 (2002).

21. Huntley, B. \& Birks, H. J. B. An Atlas of Past and Present Pollen Maps for Europe 0-13,000 Years Ago (Cambridge Univ. Press, New York, 1983).

22. Jackson, S. T., Overpeck, J. T., Webb, T., Keattch, S. E. \& Anderson, K. H. Mapped plant-macrofossil and pollen records of late Quaternary vegetation change in eastern North America. Quat. Sci. Rev. 16, 1-70 (1997).

23. Bush, M. B., Miller, M. B., De Oliveira, P. E. \& Colinvaux, P. A. Two histories of environmental change and human disturbance in eastern lowland Amazonia. Holocene 10, 543-553 (2000).

24. Dennis, B. \& Taper, M. L. Density dependence in time series observations of natural populations: estimation and testing. Ecol. Monogr. 64, 205-224.

25. Bennett, K. D. Holocene history of forest trees in southern Ontario. Can. J. Bot. 65, 1792-1801 (1987).

26. Burden, E. T., McAndrews, J. H. \& Norris, G. Palynology of Indian and European forest clearance and farming in lake sediment cores from Awenda Provincial Park, Ontario. Can. J. Earth Sci. 23, 43-54 (1986)

27. Fuller, J. L. Holocene forest dynamics in southern Ontario, Canada: fine-resolution pollen data. Can. J. Bot. 75, 1714-1727 (1997).

28. McAndrews, J. H. \& Campbell, I. D. in Proxy Climate Data and Models of the Six Thousand Years Before Present Time Interval: The Canadian Perspective (ed. Telka, A.) (Canadian Global Change Program Incidental Rep. Series IR93-3, The Royal Society of Canada, Ottawa, 1993).

29. Szeicz, J. M. \& MacDonald, G. M. Postglacial vegetation history of oak savanna in southern Ontario. Can. J. Bot. 69, 1507-1519 (1991).

Acknowledgements Research was supported by the National Science Foundation. We thank K. Bennett and P. Chesson for comments.

Competing interests statement The authors declare that they have no competing financial interests.

Correspondence and requests for materials should be addressed to J.S.C. (jimclark@duke.edu). 